\title{
A comparative study of the effect of teacher's group and individual feedback on Iranian EFL learners' learning of speech acts in apology letter writing
}

\author{
Zahra Pourmousavi and Zohre Mohamadi Zenouzagh ${ }^{*}$ (1)
}

* Correspondence: Zohre.

mohamadi@kiau.ac.ir

English Teaching and Tranalation Department, Karaj Branch, Islamic

Azad University, Karaj, Iran

\begin{abstract}
The linguistic scrutiny of any aspect of pragmatics is bound to considering carefully the context in which it is expressed. This becomes very glaring when the utterances that constitute discourse are viewed as performing social actions. In an EFL context like Iran, English language learners are in urgent need of raising their pragmatic awareness as they do not have regular access to an environment where the main language of communication is English. The major context for improving their pragmatic competence could be classroom. Thus, teachers need to cope with this issue which makes knowledge of speech acts more worthy of being dealt with. This research was an attempt to find out the effect of teacher's group feedback versus individual feedback on Iranian EFL learners' uptake of speech acts. To carry out the study, 32 pre-intermediate learners were chosen to take part based on convenient sampling through non-random grouping. To make sure that the learners were homogeneous, a Quick Placement Test (QPT) was administered before the treatment. Based on the design of the study, the learners were divided into two treatment conditions of individual and group feedback. The research was a quasi-experimental a pretest and a posttest of writing before and after the treatment to measure students' uptake of speech acts. Results of two paired-samples t-test and an independent samples t-test showed significant effect of individual feedback on learners' uptake of speech acts, while group feedback was not significant. It was also found that there was a significant difference between the effects of teacher feedback in groups vs. teacher feedback given to individual learners. The present research has significant implications. Tests can also focus more on promoting individual feedback among learners and teachers in washback effect. Teachers can also make principled decisions about the feedback condition that best boost leaner uptake in speech act.
\end{abstract}

Keywords: Teachers' group feedback, Teachers' individual feedback, Speech acts, Error correction, Writing performance, EFL learners, Uptake 


\section{Introduction}

The development of learners' communicative competence in a second and foreign language has been the major concerns for teaching professionals. Appropriate communication requires not only the knowledge of language features but also pragmatic rules. Given this need, various research has been conducted to overcome the pragmatic difficulties and help language learners to communicate successfully in the target language (Martínez-Flor \& Usó-Juan, 2010). Research has focused more on grammatical errors as causes of communicative breakdown (Ansarin \& Mohamadi, 2013; Ellis, Basturkmen, \& Loewen, 2001; Ellis, Loewen, \& Basturkmen, 2006). Meanwhile errors of appropriacy may have more negative consequence than grammatical errors since the earlier errors may characterize the non-native speaker as being uncooperative, rude and offensive (Crandall \& Basturkmen, 2004). When it comes to real-life situations, many second/foreign language learners appear to fail in displaying pragmatic competence and the case is even true for proficient language learners (DeCapua \& Dunham, 2007; Hinkel, 1997; Martínez Flor, 2005; Pishghadam \& Sharafaddini, 2011).

The reason is a fail to understand the philosophy of language which entails understanding the nature of language with its relation to its speakers, their thoughts and the world. This brings sciences such as sociolinguistics, linguistics and anthropology into account. Within these perspectives, people of different cultures have to realize crosscultural speech act realization (Wong, 2016) in order to be pragmatically efficient.

Another reason is the problems with the input. With regard to first condition, that of exposure to appropriate pragmatic input, several studies indicated that often textbooks do not present speech acts and when they do it may not reflect real language use. Much of the exposure foreign language learners have to target language is through course books which have problems with presentation of pragmatics (speech act). (Kasper, 2001). For example, the detailed examination of the eleven course books revealed that they are not adequate since the speech acts of request, refusal, complaints are presented in the course books with different coverage and frequency of refusals in the course books is much less than requests and complaints are nearly non-existent. The evaluation also demonstrated that strategies used to instruct students different speech act were no covered to the same extent (Delen \& Tavil, 2010). Similarly, Usó-Juan and Martínez-Flor (2008)'s evaluation of textbooks with respect to pramgmatic competence indicated, in text books, all the request moves are modified by request mitigating devise and presented as fixed chunks in single written sentences with no discourse context. To compensate the decontextualized presentation of speech act, audiovisual source materials were used the results of which indicated profound improvement in pragmatic competence of learners (Canning-Wilson \& Wallace, 2000). Likewise, the study by Derakhshan and Arabmofrad (2018) confirmed positive impact of video-enhanced input on the comprehension of three speech acts of apology, request, and refusal on 69 (27 males and 42 females) Iranian intermediate EFL learners who were randomly divided into four homogenous groups (i.e., metapragmatic, form-search, interactive translation, and control). However, comparison of the occurrence of speech act in film data indicated some sociolinguistic features such as gender did not correspond with natural use (Martínez Flor, 2005). This convinced the teaching professionals to consider techniques and activities to teach speech act. Recent two decades have experienced teaching professionals' quest for an appropriate method to teach for pragmatic competence which 
range from explicit to implicit instruction methods. For example, pre-post-test design with experimental and control group performance on Discourse Completion Test was administered by Rajabia, Azizifara, and Gowhary (2015) to explore the effect of explicit instruction on pragmatic performance. The results revealed that explicit instruction is a facilitative tool to develop L2 learners' pragmatic competence and overall appropriateness of speech acts production. On the implicit instruction side, the effect of using situational comedy to improve Saudi female freshman female EFL students' use of speech acts of request, refusal, apology, and compliment response was approved in a quantitative research with written discourse completion test as pre-post-test and a close-ended questionnaire by Alerwi and Alzahrani (2020).

With respect to the role of feedback, several studies have been conducted revolving around the implicitly and explicitness degree of feedbacks on speech acts. For example, Pre-test/post-test experimental study on the effect of metalinguistic explanation and recast (restating learner performance for self-correction) in response to refusal speech act indicated that both feedback types positively affected subcomponents of polite refusal strategies with having explicit feedback at higher statues (Ajabshir, 2014). Also another hybrid study investigated the effect instruction and feedback on speech act and pragmatic competence testing pragmatic markers using experimental pre-test/post design in explicit instruction only, explicit instruction with metalinguistic feedback, structured input instruction only, and structured input instruction with metalinguistic feedback indicating improvement in all groups. (Shafee Nahrkhalaji, 2013).

Although aforementioned studies were both timely and important, they are mostly on spoken language. Therefore, research is calling for more study on speech act in written language. "We need a model of the various possible relations between speaker/writer, audience and text, and case studies of real language in use which study the effects which media of transmission ( spoken vs. written) can have on illocutionary and propositional commitment. Such topics have often been the concern of sociologists, but their analyses have often lacked the analytic sophistication of speech act theory" p. (492-493) (Stubbs, 1983). And as Drid (2018) mentioned arriving at a satisfactory linguistic scrutiny of any aspect of discourse is bound to consideringcarefully the context in which it is expressed. This becomes very glaring when the utterances that constitute discourse are viewed as performing social actions.

Besides, missing from the feedback and instruction type studies is research on the design of the feedback delivery. This study is intended to investigate speech act of EFL learners in writing letters with respect to feedback delivery condition namely whether the feedback is delivered individually or in group by teachers. Thus, the purpose of the present study was three-folded. Firstly, the study aimed to explore whether teacher feedback given to individual learners has any statistically significant impact on EFL learners' uptake of speech acts. Secondly, the study sought to find whether teacher feedback in groups has any statistically significant impact on EFL learners' uptake of speech acts. Thirdly, it was an attempt to explore if teacher feedback in groups has more statistically significant impact on EFL learners' uptake of speech acts versus teachers' feedback given to individual learners. 


\section{Background and purposes}

In recent years, there has been an increasing amount of literature on error correction or feedback types in many language learning contexts. In the following paragraphs, some pertinent studies will be reviewed in this section.

\section{Feedback}

In teaching, feedback refers to comments or other information that teacher or other people give the learners regarding their achievement on learning and doing tasks. Previous research on feedback in second language writing have largely focused on the impact of feedback on grammatical accuracy (Chandler, 2003; Ferris \& Roberts, 2001) and on form and/or content (Ashwell, 2000; Fazio, 2001) revealing the very fact that second language writing research have drawn largely on research on oral feedback and types of written feedback.

It can be concluded from research on written corrective feedback that the presence of feedback seems to enhance learners' accuracy and fluency. However, it is not clear which given types and feedback combinations are effective and last over long time. One limitation of much of research on feedback in second language writing is the fact that they artificially separate either feedback focusing on given forms (e.g., nouns or sentence structure) or selected feedback types (e.g., coding, circling, or error description). This limitation causes difficulty in understanding the efficacy of a variety of feedback techniques (Ellis, 2009; Hyland \& Hyland, 2006).

Feedback plays a crucial role in revising student writing and maximizing its quality (Freedman, 1985). Through feedback, learners become familiar with their strength and weaknesses. They also monitor their progress, and if they do not perform well, through further feedback, they can correct and improve their writing (Evans, Hartshorn, McCollum, \& Wolfersberger, 2010).

In addition, feedback indicates how the students are developing their written skill, so it helps teacher to discover their weaknesses (Van Beuningen, De Jong, \& Kuiken, 2012). Moreover, by receiving feedback from the teacher, students are encouraged not to view their writing as a final product. Teacher written feedback enables students to discover the points that have led to contradiction between their intentions, and what they have written (Manchón, 2011). In addition, students can have access to teacher comments whenever they need them. "Written feedback provides a lasting record which can be used to measure progress and to act as a reminder" (Nation, 2008, p. 139).

However, if the teacher's written feedback and comments are vague, the students might not have access to teacher for further clarification (Williams, 2012). Written feedback should be given in a way that student realizes that the teacher trusts them as someone who learns (Brookhart, 2017). Straub (2000) suggests that teachers should communicate with students by giving written feedback in complete sentences.

Over the last few decades, scholars have been studying feedback on writing of high school and undergraduate students (Brannon \& Knoblauch, 1982; Ziv, 1984). They found that written feedback motivates learners to revise their drafts (Saito, 1994; Zhang, 1995), and enhances their writing (Ferris, 1997, 2010). Consequently, written feedback is the most well-known means teachers use to interact and communicate with learners (Ferris, 2004; Hyland \& Hyland, 2001). 
According to Ellis (2014), how teachers correct second language learners' writing is a topic that has attracted growing attention of researchers and teachers. However, as the recent review of the related literature on feedback on second language learners' writing (Hyland \& Hyland, 2006) indicates, notwithstanding the plethora of research in this regard, there remains many questions researchers need to address.

\section{Corrective feedback and learner uptake}

The concept of uptake has been defined in other work as what students report on their learning from a given course (Slimani, 1992). There are two types of student uptake: (a) The first one results in repair of the error, and the second one leads to any production requiring repair.

Long (1985) claimed, corrective feedback and learner uptake could be considered valuable processes for developing language development, especially when they perform the roles of modifying the interactions. Moreover, scholars like White $(1987,1989)$ have remarked that if second language learners' goal is to achieve nativelike proficiency, negative evidence is required. Since negative evidence is the response to learners' errors, it could be in the form of corrective feedback in the class interactions. Besides, Corrective feedback and learner uptake have usually been studied in the classroom research, and one of the main motives for studying the pattern of corrective feedback and uptake has been to determine sequence of error treatment in various classroom contexts (Manchón, 2011).

It is also worth studying learner uptake with respect to the concept of noticing (Schmidt, 1990; Schmidt, 1995) and attention (Gass \& Mackey, 2007). According to Gass and Mackey (2007), attention is essential and enough for drawing input from a stimulus during language learning. Uptake can show which items have been attended by the learners as a consequence of corrective feedback (Ferris, 2010). Likewise, Schmidt (1995) stated that noticing is crucial for changing input to intake. While no study has explicitly shown that uptake is an indicator of noticing, it may be assumed that learners' uptake includes some noticed linguistic features. This could be a reason why it is worth examining uptake as a sign of language development.

\section{Speech act}

Speech act is widely acknowledged as the most practical communicative dimension of language that should be learnt by foreign language learners (Carbaugh, 2013). It is believed that providing effective feedback based on the speech acts might improve the communicative functions of feedback. To do so, teachers need to understand the types of feedback which are more useful for learners' writing.

According to Richards and Schmidt (2013), in speech act theory, utterances carry two types of meaning; propositional meaning and illocutionary meaning. Propositional meaning (locutionary meaning) is the major literal meaning of the utterance conveyed through certain words and structures which the utterance includes (Kissine, 2013). Illocutionary meaning (illocutionary force), on the other hand, refers to the influence the utterance or written text exerts on the reader or listener.

There are also a variety of speech act theories two of which were employed in this research. These two were: 
1) Austin's theory of speech acts.

Austin (1975) classifies utterances within speech acts into three types including locutionary act, illocutionary acts, and perlocutionary acts.

a) Locutionary acts: Locutionary acts refer to the meaningfulness of an expression. According to Austin (1975), within speech act certain noises must be generated by the human voice: "to say anything is ... always to perform the act of uttering certain noises..., and the utterance is a phone" (p. 92). However, sounds do not always play significant roles; rather, in this level "the utterance (in writing) of the sentence" (p. 57), could be another form. Nevertheless, Austin views spoken sounds superior to any other form of reproduction. The locutionary act consists of three levels including phonetic, phatic and rhetic levels. The realization of phatic level depends on the distinction between phone and phoneme in that the former refers to the noises the speaker produces and the latter signifies sound unit of language (Kissine, 2013).

b) Illocutionary acts: The illocutionary act signifies the meaningfulness of an utterance which is motivated by performative drives. Illocutionary acts are central to the entire theory of speech acts. In fact, an illocutionary act is the action acted out by the speaker in generating a certain utterance. It is closely related to the speaker's intentions including stating, questioning, promising, requesting, giving commands, warning, etc. (Tatsuki \& Houck, 2010). Thus, the illocutionary act is acted through the communicative drive of an utterance which is also generally known as illocutionary force of the utterance. In other words, the illocutionary act shows how the entire utterance is to be used in the conversation. To perform illocutionary act, it is the intention of a subject which is significant. At this level, meaning is determined by the intention of the speaker (Petrey, 2016).

Within illocutionary act, various performative verbs are used depicting both obvious and ambiguous actions. In fact, it is not the first level which determines the outcome of performative utterances since they are just some phones sticking together according to conventional rules of lexicon and syntax (Purver, Gregoromichelaki, \& Cann, 2010). The interpretation of the speech acts at the level of illocutionary acts is dependent upon their cultural context. The misunderstanding is rooted in the cultural differences at the level of illocutionary act since the addressee is unable to understand the speaker's intention and fails to perform the act (Röver, 2014).

c) Perlocutionary acts: The perlocutionary act refers to the meaningfulness of an utterance in which a certain conventional utterance results in a certain outcome. Perlocutionary acts are performed to exert an influence on the hearer. Sometimes, it might appear that perlocutionary acts do not differ from illocutionary acts; however, there is a significant feature which can be used as the base for their difference (Roever, Fraser, \& Elder, 2014). Therefore, the difference lies in the comprehension of the intention and the actual performance of the intention. There are many utterances to exert influence on the hearer and to convey the information directly. Others are more careful or polite and are used indirectly to transmit the message. Subjects do 
not "create an utterance with a function without intending it to have an effect" (Yule, 2016, p. 48). They presuppose that the hearer will comprehend the effect the subject desires. In Austin's words, perlocutionary act is "the bringing about of effects on the audience by means, of uttering the sentence, such effects being special to the circumstances of utterance" (1975, p. 236).

2) Searl s theory of speech acts.

Searle (1975) believes that the speech act is the basic unit of meaning and force, or the most basic linguistic entity with both constitutive and performative dimensions. He also acknowledges that there are illocutionary and perlocutionary acts. His understanding of the latter is similar to that of Austin but his understanding of the former is quite different.

He classifies illocutionary acts based on several important pragmatic parameters. $\mathrm{He}$ believes language performs different speech acts like statements, commands, requests or promises. He takes the view that speech acts are only explained by particular norms that are neither semantic not pragmatic.

His five-part classification of speech acts is well explained as follows:

a. commissive: a speech act that commits the speaker to doing something in the future, such as a promise or a threat. For example:

If you don't stop fighting I'll call the police. (threat).

I'll take you to the movies tomorrow. (promise).

b. declarative: a speech act which changes the state of affairs in the world.

For example, during the wedding ceremony the act of marriage is performed when the phrase I now pronounce you man and wife is uttered.

c. directive: a speech act that has the function of getting the listener to do something, such as a suggestion, a request, or a command. For example:

Please sit down.

Why don't you close the window.

d. expressive: a speech act in which the speaker expresses feelings and attitudes about something, such as an apology, a complaint, or to thank someone, to congratulate someone. For example:

The meal was delicious.

e. representative: a speech act which describes states or events in the world, such as an assertion, a claim, a report. For example, the assertion:

This is a German car (Searle, 1975, p. 543). 


\section{Teaching writing}

As a discovery process, teaching writing attempts to make students familiar with the nature of the writing process while providing teacher and peer with collaboration and intervention opportunities during the process as they discuss meaning (Reid, 1994; Susser, 1994). During such process, the teacher and students brainstorm, write journals, draft many times, exchange feedbacks and revise and edit to read and comment on the writing to enhance the final writing product (Ahmed, 2010). As second language writers are different from English-speaking writers in terms of their writing practices and needs (Krapels, 1990; Silva, 1993), it is necessary to study the effect of multiple drafting, revision, and the role of feedbacks given by teacher and peer on both learners' revisions and the entire quality of their composition (Coffin et al., 2005).

Researchers argue that structuring the writing class and the type of feedback given to learners will undoubtedly affect learners' approach to writing process, feedback, and revisions (Hedgcock \& Lefkowitz, 1996; Lockhart \& Ng, 1995). Zamel (1983) and Cohen (1987) found that lack of second language learners' writing and revision strategies are rooted partly in writing teachers who focus mainly on the form of the writing and overlook the real ideas and meaning interacted through the text. As Leki (2002) and Susser (1994) remark, however, the shift of trend has not removed the problems of providing effective feedback. Writing teacher themselves are usually dubious about the best ways of giving feedback to their learners (Hyland, 2015).

\section{Letter writing}

Letters are a very common form of writing knowing the rules to write them is a critical point since they can make all the difference and leave long-lasting effects as Bly (2011) stated. He further explained that such impressions are prominent as they can get the reader to do what you want them to do if you have been successful in making yourself completely understood. The major points Bly (2011) strongly recommended to keep in mind for writing an effective letter are first to do a SAP analysis which is an acronym for the three words of "Subject, Audience, and Purpose". That is, you need to pay careful attention to the content and organization of the letter including the topic or the subject, the audience, as well as the purpose for what you write a letter. Second; he emphasized on gathering information and doing the necessary research to get to know the requirements of the kind of letter you are about to write. Finally, making an outline of whatever necessary to be mentioned is the point you should never ignore, and lastly, you can sit down and start writing the letter.

Letter of apology, which is the kind of letter used as the instrument in the present study, is then the type of letter in Podesta and Paxton's (2003) word used in the case you have had a difficulty or a conflict with somebody and you want to set the things right. It is beneficial since it lets the other party to accept your apology without the probability of starting another argument.

The point to be remembered is that in writing any kind of letter, you have to take some points such as the format, style/ tone/ voice, structure, handy phrases, and sincere regrets into account (Bly, 2011). In an apology letter, however, you need to apologize unconditionally, admit that you have been wrong, admit the blame, and try not to 
mention any previous occasions in which the other party had something wrong to you (Podesta \& Paxton, 2003).

\section{The relationship between speech act and EFL writing}

As Cohen (2010) stated, the probability of learners' acquiring the speech acts they contact more, notice more, and need more is higher. Apology is then the most frequently used type of speech act human beings used in their interactions. They are utilized mostly in situations when the social relationships between the parties are ruined as a result of using a linguistic expression that has been insulting or offending to another party. If a speaker does not make an apology subsequently, the problem would not be solved as the other party's face has been threatened (Haji Maibodi, 2016).

Since making apologies is an important point in maintaining the communication, in both oral and written form, therefore it is an equally important point to consider them from a language learning perspective. Another point to be mentioned is that making apologies is a difficult speech act for learners sine they are very challenging and demanding for L2 learners. Such a difficulty is basically due to the fact that apologies include feelings of disgrace and the need for compensations on the part of a language learner (Abdi, 2014). That is to say, knowing how to produce apologies is another point as important as the matter of apologizing itself. The matter becomes even more complicated when the learners are to make them in a second/foreign language (EFL) and in written form (Haji Maibodi, 2016).

As a result, the researcher of the present inquiry decided to explore whether teacher feedback given to individual EFL learners has any statistically significant impact on their uptake of speech acts. It also sought to find whether teacher feedback in groups has any statistically significant impact on EFL learners' uptake of speech acts. It was an attempt to explore if teacher feedback in groups has more statistically significant impact on EFL learners' uptake of speech acts versus teachers' feedback given to individual learners.

To fulfill the purpose of this study, the following research questions were addressed:

RQ1: Does teacher's individual feedback have any statistically significant effect on EFL learners' uptake of speech acts?

RQ2: Does teacher's group feedback have any statistically significant effect on EFL learners' uptake of speech acts?

RQ3: Is there any statistically significant difference between the effects of teacher's group feedback versus individual feedback on EFL learners' uptake of speech acts?

\section{Method}

In this section, the methodology of this research, including the participants, instruments used for data collection, data collection procedures, the design of the study and ways of data analysis are presented.

\section{Participants}

The participants of this research were 32 Iranian EFL students studying in Islamic Azad University in Karaj, Iran. Their ages ranged from 20 to 30 and their level of proficiency 
in English was pre-intermediate These participants were chosen from among 62 Iranian EFL students after homogenization test, which was a Quick Placement Test (QPT). After the homogenization test, the participants were assigned to two groups of 16 students. It is also important to note that these students were both males and females. Table 1 shows the demographic characteristics of the participants.

\section{Instrumentation}

The instruments that were used to collect the required data from the learners were a QPT test, a writing pretest, and a posttest to find out if there was a difference between the results of the pretest and posttest. These instruments are described in detail in the following sections:

\section{Homogenization test}

To homogenize the learners before the treatment, it was important to make sure that they were more or less at the same level of proficiency in English language for more reliable results. For this purpose, a Quick Placement Test (QPT) was used (Appendix A). The test had 60 questions. From among 62 participants, 32 of those whose scores ranged between 1 score above and 1 score below standard deviation was chosen to take part in the study.

\section{Writing pretest and posttest}

After the homogenization, a writing pretest (Appendix B) was administered to the participants to find out their level of writing to be compared to the writing posttest for any possible differences and effects of the two types of feedback on their uptake of speech acts. These tests were taken from the book a Concise Guide to Letter Writing by Amini and Aghvami (2009), Model Business Letters, Emails and Other Business Documents by Taylor (2015), and websites such as www.nplag.com, www.dcielts.com, www. whitesmoke.com, www.manythings.org, www.yourdictionary.com, www.apologyletters. net, www.perfectapology.com, www.writeexpress.com, and www.wikihow.com. This test served as the starting point of the treatment based on which the course was designed.

After the treatment phase, another test of writing was administered to the learners to find out how much their uptake of speech acts have been changed as a result of the

Table 1 Demographic information of the participants

\begin{tabular}{|c|c|c|}
\hline \multicolumn{2}{|l|}{ Number } & 32 \\
\hline \multicolumn{2}{|l|}{ Age } & $20-30$ \\
\hline \multicolumn{2}{|l|}{ Nationality } & Iranian \\
\hline \multicolumn{2}{|l|}{ Proficiency level } & Pre-intermediate \\
\hline \multicolumn{2}{|c|}{ Language institute } & $\begin{array}{l}\text { EFL department } \\
\text { Islamic Azad University, Karaj, Branch }\end{array}$ \\
\hline \multicolumn{2}{|c|}{ Language background } & native speakers of Farsi \\
\hline \multirow[t]{2}{*}{ Gender } & Female & 17 \\
\hline & male & 16 \\
\hline \multirow[t]{2}{*}{ Research group } & Individual teacher feedback & $16($ female $=7$, male $=9)$ \\
\hline & Group teacher feedback & $16($ female $=10$, male $=6)$ \\
\hline
\end{tabular}


treatment. For this purpose, another similar writing test (Appendix D) was given to the learners, however with a different subject. It is also important that the level of the writing in both pretest and posttest was the same with the same scoring.

"To guarantee the generalizability of the results of a research to the population, the tests used need to be reliable. Hence, the researcher checked the inter-rater reliability of the pretest and posttest of the teacher corrective feedback through the parametric kind of correlation, i.e. Pearson Correlation, due to the fact that the researcher's focus was on the participants' writing ability and the data was normal.

Table 2 shows the results of Pearson Correlation between the teachers' scores on the pretest and posttest of the teacher corrective feedback group.

According to the reliability index of the two sets of scores announced by Muijs (2004), the Pearson correlation is considered strong where the values are above .8 and, the closer the value to $+/-1$, the stronger the correlation will be. Bearing the point in mind and checking the Pearson values in Table 6, the conclusion is that both sets of scores were strongly correlated because the inter-rater reliability of the pretest and the posttest of the teacher corrective feedback are .99 and .98 respectively, and are slightly below one. That is to say, the tests used in this study had acceptable reliability which enables the researcher to safely generalize the results.

\section{Data collection procedure}

The ways of collecting the data and the details of what has been done in this research to collect the data are presented in this section.

First of all, a homogenization test was administered to the learners for the purpose of sampling. This test was necessary to make sure that the students were all at the same level of proficiency in English language. For this purpose, a QPT test was administered and the learners had $30 \mathrm{~min}$ to answer the questions. The students whose scores were 1 unit above and 1 unit below the standard deviation were chosen to take part in the study.

After the homogenization, 32 learners were chosen to take part and they were grouped into two groups of 16 . Then a pretest was given to the learners to set the starting point of the treatment. The pretest served as an inventory of the learners' errors based on which the feedbacks that the teacher was meant to give them were designed. In each group a different type of feedback was used. In one of the groups, individual feedback was used and in the other group, group feedback was used.

The treatment went on for 5 sessions of 20 min each for each apology letter of formal, informal and business. Therefore, overall number of treatment sessions was 15 . Each treatment sessions lasted $20 \mathrm{~min}$ for instruction and $20 \mathrm{~min}$ of teacher feedback.

Table $\mathbf{2}$ Inter-rater reliability of the pretest and posttest scores of the teacher corrective feedback group (TCG)

\begin{tabular}{llcc}
\hline & & TCG, Pre, 2nd teacher & TCG, Post, 2nd teacher \\
\hline TCG, Pre,1st rater & Pearson Correlation & .99 & \\
& Sig. (2-tailed) & $.00^{*}$ & \\
TCG, Post, 1st rater & Pearson Correlation & & .98 \\
& Sig. (2-tailed) & & $.01^{*}$ \\
\hline
\end{tabular}


In both groups, the students were taught the same thing about speech acts, which was writing apology letters in three forms: formal, informal and business apology letters. The learners were required to do a writing assignment after each session. To make it easier for them to understand the assignment, a sample was given to them. Six strategies for apology proposed by Al Masaeed, Waugh, and Burns (2018) were explicitly instructed in both groups. They include a) a device indicating illocutionally force which is a statement of remorse or regret, b) an expression of responsibility for the offence, c) an account of the reason for the offense, d) an offer of repair, e) a promise of forbearance, and f) an expression of concern for the offended party. Both research groups were managed by the teachers so that the topics of writing letters, teacher feedback types, the duration of instruction. The groups were only different in terms of feedback delivery conditions which are one group having received teacher group feedback and one group having received teacher individual feedback.

In the group that was meant to receive individual feedback, the learners received feedback from the teacher for their writing tasks individually. This individual feedback was delivered to them through an online messaging app, Telegram. In the group that was supposed to receive group feedback, a group was created in the messaging app with all of the 16 students added to the group. The teacher delivered the feedback on their writing in the group so that other students would see the comments and learn from the comments the teacher gave on their classmates' writing assignment. The details of assignments that were given to the learners are presented in Appendix $\mathrm{C}$.

After the treatment, a posttest of writing was given to the learners to find out the possible effect of the two types of feedback on their uptake of speech acts. The level of the writing posttest was the same as the pretest and both groups had the same topics to write about. A sample of pretest, posttest and assignments of one of the students is provided in Appendix E.

\section{Scoring of uptake}

Due to the fact that uptake is considered by the researchers as how much the feedback was effective and has rendered correct responses by the learners in the posttest followed by the feedback, the learners' writing posttests were given a mark based on the following rubric designed by the researcher based on Taylor (2015), Amini and Aghvami (2009) and websites such as www.nplag.com, www.dcielts.com, www.whitesmoke.com, www.manythings.org, www.yourdictionary.com, www.apologyletters.net, www.perfectapology.com, www.writeexpress.com, and www.wikihow.com (Table 3).

For each of the above factors that the students did not consider in their writing, a major point (A, B, C, D) was taken from them. But if none of the above points were seen in their writing, their score would be $\mathrm{D}-($ Table 4$)$. The range of marks that were given to the learners' writing is as follows:

Table 3 Scoring rubric (major points)

Express your regret and sorrowfulness

Explain why you must apologize

Propose an alternative plain (if appropriate)

End courteously 
Table 4 Range of marks

\begin{tabular}{lccccccccccccccccccc}
\hline $\mathrm{A}++$ & $\mathrm{A}+$ & $\mathrm{A}$ & $\mathrm{A}-$ & $\mathrm{A}--$ & $\mathrm{B}++$ & $\mathrm{B}+$ & $\mathrm{B}$ & $\mathrm{B}-$ & $\mathrm{B}--$ & $\mathrm{C}++$ & $\mathrm{C}+$ & $\mathrm{C}$ & $\mathrm{C}-$ & $\mathrm{C}--$ & $\mathrm{D}++$ & $\mathrm{D}+$ & $\mathrm{D}$ & $\mathrm{D}-$ & $\mathrm{D}--$ \\
\hline 20 & 19 & 18 & 17 & 16 & 15 & 14 & 13 & 12 & 11 & 10 & 9 & 8 & 7 & 6 & 5 & 4 & 3 & 2 & 1
\end{tabular}

Furthermore, these scores were broken down to four other minor factors as the following:

Scoring Rubric for General Apology Letters (Minor Points)

\section{Tips}

To the point

Apologize unconditionally

Admit you were wrong. Accept the blame even if the other person is not in fact

blameless

Be the bigger person. Don't be pretty or search for ways in which they previously did you wrong as a way of compensating for today's apology

The above table indicates the scoring rubric in for general apology letters (Table 5). However, for business letters, other tips were considered which are as follows:

From among the above minor points, if they did not consider one of them was not considered, a + was taken from them, if they did not consider two of them, another + was taken from them. But if three or more tips were not considered, their score would fall a major point, for example from A to B, etc.

It is also very important to note that as learning is different from uptake, the scores that were given to the learners' writing were not simple scores and did not represent their learning and how much correct their writings were. However, the marks that were given to their writing were based on how much the feedback was effective and heeded in the posttest. Therefore, the marks do not represent learning, but rather they are representation of the amount of uptake happened based on the teacher's feedback.

\section{Data analysis}

To analyze the data collected for the purpose of this study both descriptive and inferential statistics using SPSS version 21 was used. Concerning descriptive statistics, means and standard deviation and variances of the scores are reported. As for inferential statistics, an independent-samples t-test was run, as there were two groups whose mean scores were needed to be compared with each other.

Table 5 Scoring rubric for business apology letters (minor points)

Tips
Useful expressions for starting the letter: on the be halt of ... /we at ...
Ask for reader to accept your apology
Summarize what happened
Offer remedies
Only blame yourself
Don't use the common "sorry, but" formula




\section{Findings of the study}

In this section, the results of the data analysis are presented with its associated tables and graphs.

The effect of teacher feedback given to individual learners on their uptake of speech acts The first research question was aimed at finding if individual teacher feedback has a significant effect on the EFL learners' uptake of speech acts. A paired-samples t-test was run to compare the individual teacher feedback group's means on the pretest and posttest of speech acts test in order to probe the first null-hypothesis. Based on the results displayed in Table 6 it can be claimed that the individual feedback group had higher mean on the posttest of speech acts $(M=14.56, S D=5.03)$ than pretest $(M=$ 7.94, $\mathrm{SD}=5$ ).

The results of the paired-samples t-test ( $\mathrm{t}(15)=3.82, p=.002$, 95\% CI [2.92, 10.32], $\mathrm{r}=.702$ representing a large effect size) (Table 6) indicated that the individual feedback group had a significantly higher mean on the posttest of speech acts than pretest. Thus the first null-hypothesis as "teacher feedback given to individual learners did not have any statistically significant effect on EFL learners' uptake of speech acts" was rejected (Table 7) (Fig. 1).

The effect of teacher feedback in groups on EFL learners' uptake of speech acts

The second research question was aimed at finding out if teacher feedback given in group has a significant effect on the EFL learners' uptake of speech acts. A pairedsamples t-test was run to compare the teacher feedback given in group's means on the pretest and posttest of speech acts test in order to probe the second null-hypothesis. Based on the results displayed in Table 6 it can be claimed that the in group feedback group had higher mean on the posttest of speech acts $(M=9.69, S D=5.46)$ than pretest $(\mathrm{M}=7.75, \mathrm{SD}=4.21)$ (Table 8).

The results of the paired-samples t-test ( $\mathrm{t}(15)=1.19, p=.250,95 \%$ CI $[-1.51,5.38]$, $r=.294$ representing a weak effect size) (Table 6) indicated that the in group feedback group did not have a significantly higher mean on the posttest of speech acts than pretest. Thus the second null-hypothesis as "teacher feedback given in group learners did not have any statistically significant effect on EFL learners' uptake of speech acts" was supported (Table 9) (Fig. 2).

The significant difference between the effects of Teacher's group feedback versus individual feedback on EFL learners' uptake of speech acts

An independent $\mathrm{t}$-test was run to compare the individual and in group teacher feedback groups' means on the posttest of speech acts in order to explore the second nullhypothesis. Based on the results displayed in Table 6 it can be claimed that the

Table 6 Descriptive statistics; pretest and posttest of speech acts (individual feedback)

\begin{tabular}{llllll}
\hline & & Mean & $N$ & Std. Deviation & Std. Error Mean \\
\hline Tests & Pretest & 7.94 & 16 & 5.000 & 1.250 \\
& Posttest & 14.56 & 16 & 5.033 & 1.258 \\
\hline
\end{tabular}


Table 7 Paired-samples t-test; pretest and posttest of speech acts (individual feedback)

\begin{tabular}{|c|c|c|c|c|c|c|c|}
\hline \multicolumn{5}{|c|}{ Paired Differences } & \multirow[t]{3}{*}{$\mathrm{t}$} & \multirow[t]{3}{*}{ Df } & \multirow{3}{*}{$\begin{array}{l}\text { Sig. } \\
(2- \\
\text { tailed) }\end{array}$} \\
\hline \multirow[t]{2}{*}{ Mean } & \multirow{2}{*}{$\begin{array}{l}\text { Std. } \\
\text { Deviation }\end{array}$} & \multirow{2}{*}{$\begin{array}{l}\text { Std. } \\
\text { Error } \\
\text { Mean }\end{array}$} & \multicolumn{2}{|c|}{ 95\% Confidence Interval of the Difference } & & & \\
\hline & & & Lower & Upper & & & \\
\hline 6.625 & 6.937 & 1.734 & 2.929 & 10.321 & 3.820 & 15 & .002 \\
\hline
\end{tabular}

individual feedback group $(M=14.56, S D=5.03)$ had a higher mean on the posttest of speech acts than the in group feedback $(M=9.69, \mathrm{SD}=5.48)$ (Table 10).

The results of the independent $\mathrm{t}$-test $(\mathrm{t}(30)=2.619,95 \%[1.07,8.67], p=.014$, $\mathrm{r}=.430$ representing a moderate to large effect size) (Table 6) indicated that the individual feedback group had a significantly higher mean on the posttest. Thus the third null-hypothesis as "there is not any significant difference between the effects of teacher feedback in groups vs. teacher feedback given to individual learners on EFL learners' uptake of speech acts" was rejected.

It should be noted that the assumption of homogeneity of variances was met (Levene's $\mathrm{F}=.373, p=.546$ ). That is why the first row of Table 6, i.e. "Equal variances assumed" was reported (Table 11) (Fig. 3).

\section{Discussion}

Results of the current study can be compared and contrasted with results of other studies carried out in the field of feedback. It is also important to notice that in the literature, as stated before, group feedback is sometimes referred to as conferencing, and therefore, some of the studies below have used this term. A number of these studies are reviewed in this section, as follows:

Furthermore, Brookhart (2017) argues that giving individual feedback to learners has two benefits for the learners, because they can be more specific to the student's certain learning needs and because it is private. He further states that giving feedback

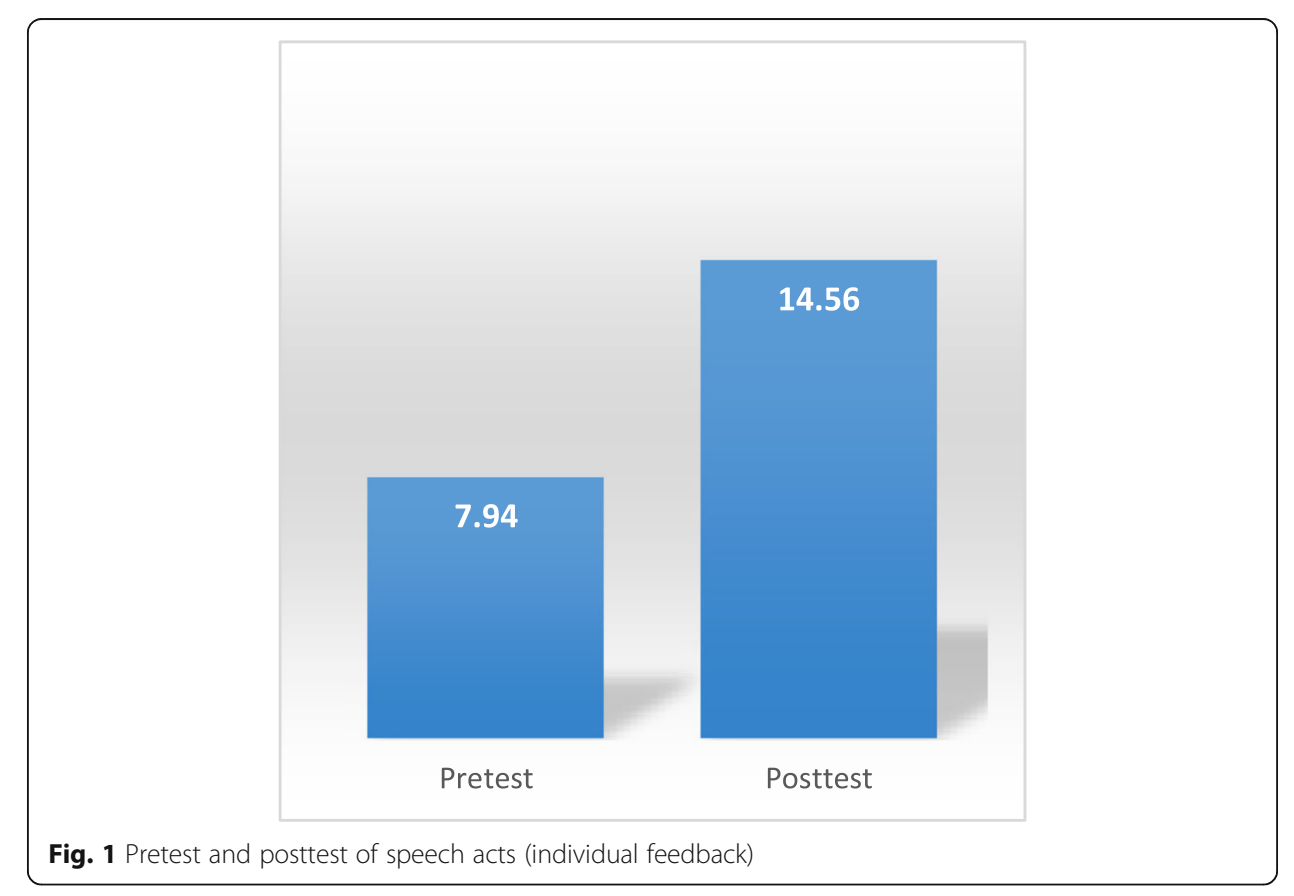


Table 8 Descriptive statistics; pretest and posttest of speech acts (in group feedback)

\begin{tabular}{llllll}
\hline & & Mean & N & Std. Deviation & Std. Error Mean \\
\hline Tests & Pretest & 7.75 & 16 & 4.219 & 1.055 \\
& Posttest & 9.69 & 16 & 5.486 & 1.371 \\
\hline
\end{tabular}

individually to learners which is more specific to them means that the information can be more useful. Furthermore, as he asserts, when the learners are given feedback in private, they will not have to worry about their peers' reactions. Therefore, "the teacher helps the student avoid some of the ego protection and face-saving that can get in the way of feedback" (p. 128). This is in line with the findings of this study in that individual feedback yields better results than group feedback mostly because of the same reasons. Both this study and that of Brookhart (2017) argue that giving feedback to learners out of the group is more beneficial for learners.

In a study carried out by Yang, Badger, and Yu (2006), examined whether peer feedback provided a resource for more feedback in writing classes in the Chinese context. They gathered a sample of students and divided them into two groups for writing essays on the same topic. One of their groups received feedback from the teacher and one from their peers. The results of their study showed that students who were exposed to teacher and peer feedback both improved their writing but teacher feedback revealed to improve their writing more than the other type of feedback. By comparing the results with those of the current research study, it can be discussed that the authority of the person who gives feedback is a determining factor in the correction of the error. Therefore, it can be said that when the teacher gives individual feedback instead of group feedback, he or she establishes a more authority with the student in a one-onone manner, and that is what Yang et al.'s (2006) study has found in general.

In another study that had different results from the results of this study was done by Bitchener, Young, and Cameron (2005), in which they investigated whether "the type of feedback (direct, explicit written feedback and student-researcher 5 minute individual conferences; direct, explicit written feedback only; no corrective feedback)" had different results on students' writing accuracy. They had 53 adult students and gave them feedback on these three types of error: a) prepositions, b) the past simple tense, and c) the definite article. They found "a significant effect for the combination of written and conference feedback on accuracy levels in the use of the past simple tense and the definite article in new pieces of writing" but no general effect on accuracy for feedback types in single groups (p. 64). One of the reasons that the current study found a different result to that of Bitchener et al. (2005) in individual conference with the students can be because of the fact that they studied a more straightforward part of the language, which is grammar and grammatical mistakes. However, the current study tended to investigate a higher-level aspect of a language, which is speech acts, which individual conference can be helpful for.

Table 9 Paired-samples t-test; pretest and posttest of speech acts (in group feedback)

\begin{tabular}{|c|c|c|c|c|c|c|c|}
\hline \multicolumn{5}{|c|}{ Paired Differences } & \multirow[t]{3}{*}{$\mathrm{t}$} & \multirow[t]{3}{*}{ Df } & \multirow{3}{*}{$\begin{array}{l}\text { Sig. } \\
\text { (2-tailed) }\end{array}$} \\
\hline \multirow[t]{2}{*}{ Mean } & \multirow{2}{*}{$\begin{array}{l}\text { Std. } \\
\text { Deviation }\end{array}$} & \multirow{2}{*}{$\begin{array}{l}\text { Std. } \\
\text { Error } \\
\text { Mean }\end{array}$} & \multicolumn{2}{|c|}{ 95\% Confidence Interval of the Difference } & & & \\
\hline & & & Lower & Upper & & & \\
\hline 1.938 & 6.475 & 1.619 & -1.513 & 5.388 & 1.197 & 15 & .250 \\
\hline
\end{tabular}




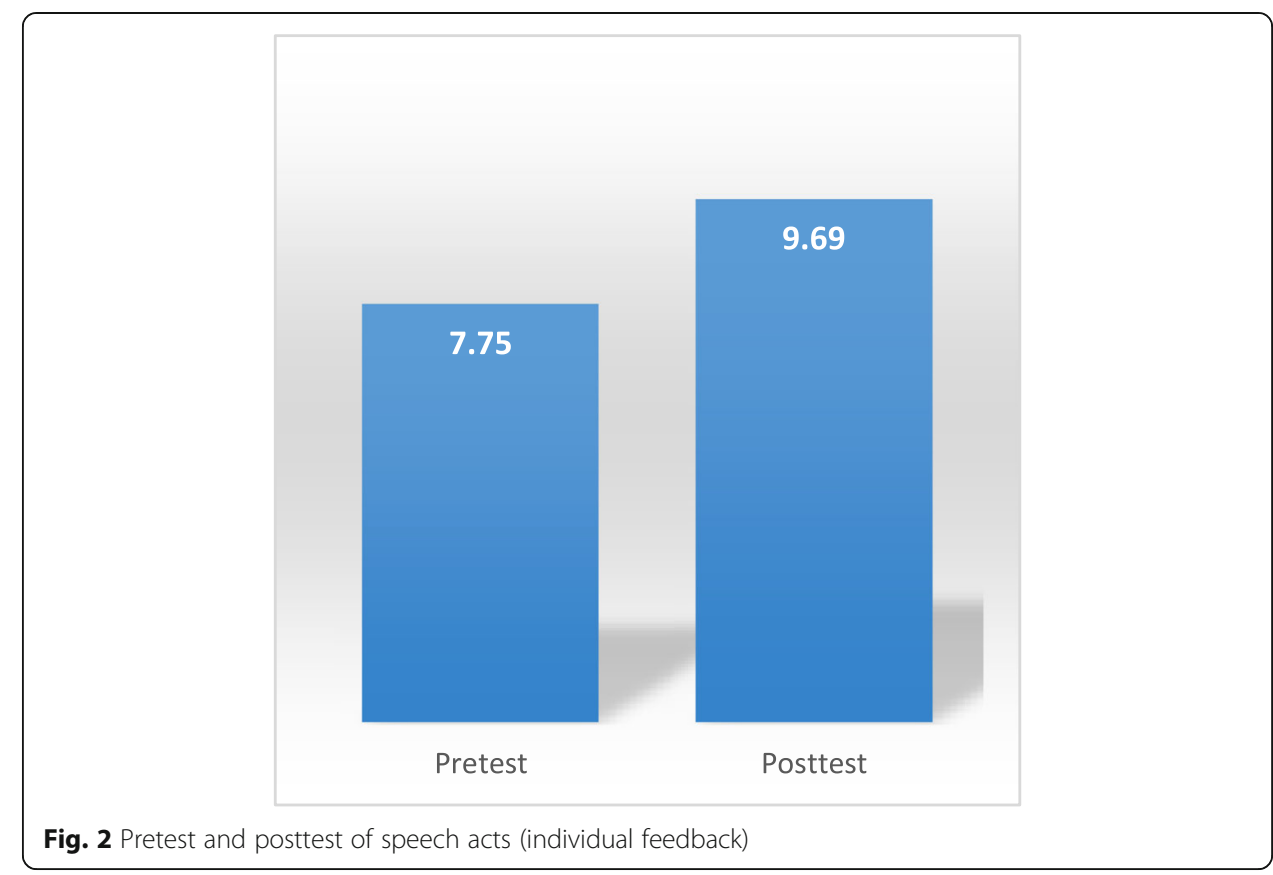

The difference in the upshots provided through the Bitchener et al. (2005) and the current inquiry can be related to the combination of using both individual and group feedback as the treatment whereas in the case of the present study they were used separately.

In another different study, Thambirajah and Nordin (2014) examined teacher-student feedback conferences for their effects in a writing course conducted in a college. The conferences in these classes were held in groups that had one teacher and six participants. Their study "included the right for the teacher to offer advice and to criticize, which is often considered to be threatening in more normal contexts" (p. 43). The results of their research showed that conference feedback should be analyzed with regard to interaction and that "situated and contextual detail is relevant to its analysis" (p. 47). They also suggest that those teachers who teach second language writing classrooms have to provide conference feedback to their learners so that they can understand what is expected of them from the side of the teachers.. In finding the sources of discrepancy between these two research studies, it can be discussed that culture may have played a role in how learners digest and accept feedback as appropriate. In some cultures, learners may be OK with teacher giving them feedback in front of their peers, but in some other cultures, this may not be the case.

As stated by Brookhart (2017), out-of-class conferencing can be very effective in classes. He reports the results of a study in which a middle school teacher who, with good intentions, asked a student to stay after school so she could help him with some aspects of his work that she just couldn't address in her large, active class. But the

Table 10 Descriptive statistics; posttest of speech acts by groups

\begin{tabular}{llllll}
\hline & Feedback & $N$ & Mean & Std. Deviation & Std. Error Mean \\
\hline Posttest & In Group & 16 & 9.69 & 5.486 & 1.371 \\
& Individual & 16 & 14.56 & 5.033 & 1.258 \\
\hline
\end{tabular}


Table 11 Independent samples t-test; posttest of speech acts by groups

\begin{tabular}{|c|c|c|c|c|c|c|c|c|c|}
\hline & \multicolumn{2}{|c|}{$\begin{array}{l}\text { Levene's } \\
\text { Test for Equality of Variances }\end{array}$} & \multicolumn{7}{|c|}{ t-test for Equality of Means } \\
\hline & \multirow[t]{2}{*}{$\bar{F}$} & \multirow[t]{2}{*}{ Sig. } & \multirow[t]{2}{*}{$\bar{T}$} & \multirow[t]{2}{*}{$d f$} & \multirow[t]{2}{*}{$\begin{array}{l}\text { Sig. } \\
\text { (2-tailed) }\end{array}$} & \multirow[t]{2}{*}{$\begin{array}{l}\text { Mean } \\
\text { Difference }\end{array}$} & \multirow[t]{2}{*}{$\begin{array}{l}\text { Std. Error } \\
\text { Difference }\end{array}$} & \multicolumn{2}{|c|}{$\begin{array}{l}95 \% \\
\text { Confidence Interval } \\
\text { of the Difference }\end{array}$} \\
\hline & & & & & & & & Lower & Upper \\
\hline $\begin{array}{l}\text { Equal } \\
\text { variances } \\
\text { assumed }\end{array}$ & .373 & .546 & 2.619 & 30 & .014 & 4.875 & 1.861 & 1.074 & 8.676 \\
\hline $\begin{array}{l}\text { Equal } \\
\text { variances } \\
\text { not } \\
\text { assumed }\end{array}$ & & & 2.619 & 29.780 & .014 & 4.875 & 1.861 & 1.073 & 8.677 \\
\hline
\end{tabular}

student felt he was being punished for not doing good work. Therefore, he suggests that these conferencing techniques can be done outside of class for further convenience. He concludes that sometimes you can take advantage of an opportunity and turn a situation into an out-of-class conference. Apart from the 'in class' and 'out of class' aspects of Brookhart's (2017) study, the difference between its results with the current study is the negative feeling of the learner for being talked to and given feedback individually, whereas this study found individual feedback to be more effective. The age, gender, and other individual differences can be the sources of discrepancy between the results of these two studies.

Furthermore, speech act of apology, which was the focus the present paper, was the subject on which Haji Maibodi (2016) worked on. She investigated the effects individual differences such as language proficiency, gender, and age might have on producing speech act of apology. Working with 187 Persian EFL university students at three academic levels of undergraduates, postgraduates and $\mathrm{PhD}$, she came to the conclusion that individual differences can be counted as an influencing factor on the learners' performance. Putting the results of this research together with the present one makes it

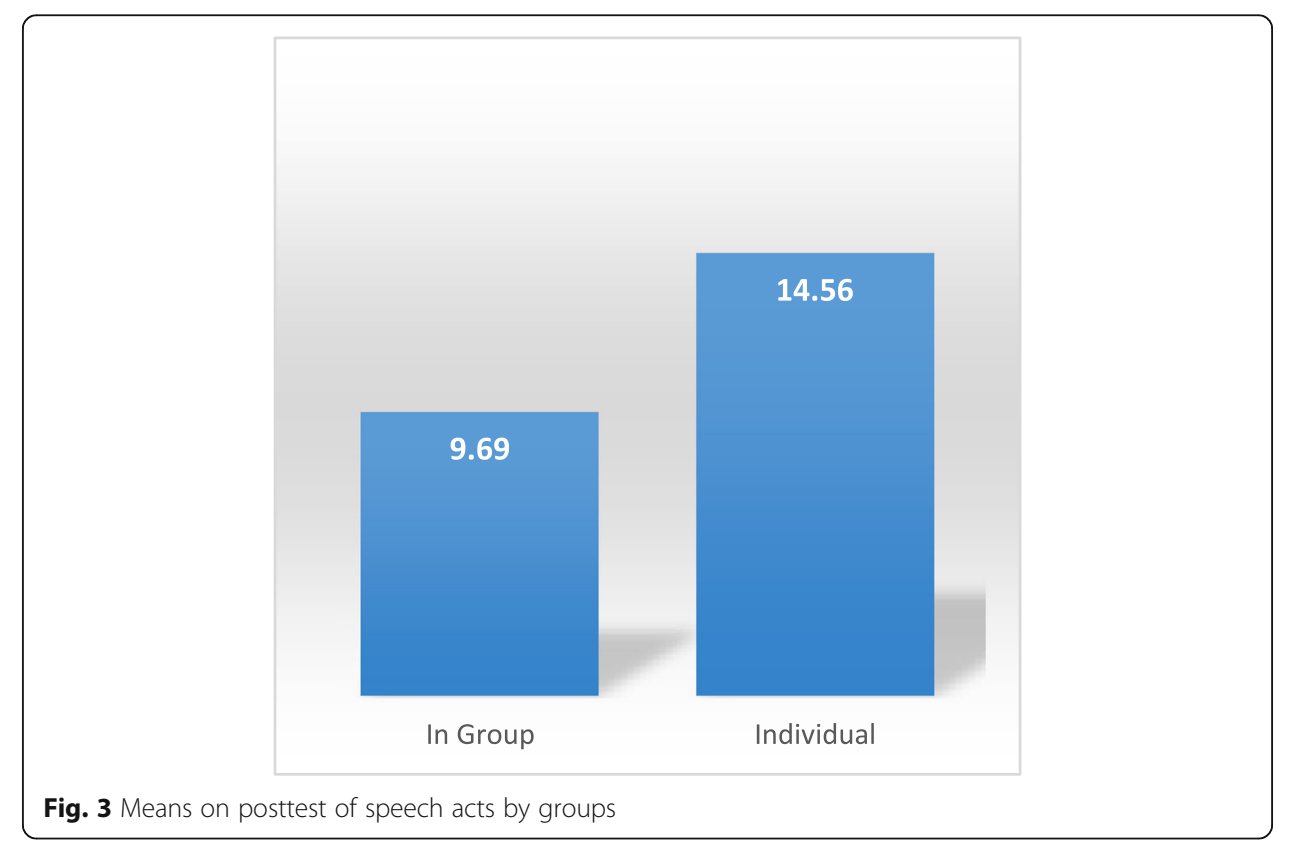


clear that feedback and the way the teacher provides it to the learners are not the only elements that cause changes on the way learners perform and individual factors also play a role.

The function for which a rating scale is used is also shown to be influential in $\mathrm{Li}$, Taguchi, and Xiao (2019) who investigated the effect different functions, based on which a production is assigned a score, have in assessing speech act production. In their inquiry, they mainly focused on communicative function, situational appropriateness, and grammaticality and at the end, they found that rating scale functioning varied across different raters, different speech acts, and different proficiency levels. Comparing the outcomes of their study with the current one, the conclusion is that which function of the speech act is going to be checked is also important when a learner's production is assessed.

Finally, to be more precise in scoring written speech act performance of the learners, Chen and Liu (2016) carried out a study with the major purpose of developing a scale to evaluate the speech act performance. To this end, they carried out a qualitative analysis of the comments provided by American raters on learners' scripts who responded some apology and request written discourse completion task situations. The upshots of their research showed that features such as the amount of the information, politeness, clarity, and relevance as well as the forms such as grammar, phrasing, and word choice are the prominent forms in the raters' viewpoint.

To justify the results of the current study in comparison to the above-mentioned research done in the field of feedback, cultural aspects of the target context must be taken into account. In some cultures, such as the Iranian and oriental cultures, giving feedback to the learners individually gives them a sense of more attention and relief. In fact, learners may feel more comfortable when their mistakes are not made public to the class.

Another aspect that may have affected the results of the current study and yielded different results than the above research is that most of them have not compared individual with group feedback. When these two types of feedback are compared, the cultural, social and other factors may come into consideration, which can have profound impacts on the results.

The use of technology can also be another factor that contributed to the different results. None of the above studies have carried out their experiment in the social media context. This can be a very important factor because these conferences have been done outside of the class, whereas most of the other studies have been done inside the class. The characteristics of the social media may be very different from other types of communication, which may have resulted in different results.

Lastly, regarding speech act, and writing aspects focused on in the course of the present study, it was found out that the context in which feedback is provided to the learners, functions, special features or forms on the basis of which a learner's production is assessed along with many other factors are important and must be taken into account.

\section{Conclusion and implications}

This study was an attempt to find out if a) teacher's feedback given to learners individually has any significant effect on leaners' uptake of speech acts, b) teacher's 
feedback given to students in groups has any significant effect on leaners' uptake of speech acts, and c) there is a significant difference between the two types of feedback on learners' uptake of speech acts.

To find out the results, two paired samples t-test and one independent samples t-test were carried out. The results of data analysis indicated that while teacher's individual feedback had a statistically significant effect on learners' uptake of speech acts. This means that those learners who got feedback individually, outperformed the other group in uptake of speech acts.

The results of the second research question showed that teacher's feedback given to learners in groups did not have a statistically significant effect on learners' uptake of speech acts. In other words, those learners who were in the group of receiving group feedback on their writing, did not improve significantly in uptake of speech acts when their pretest and posttest results were compared with each other.

As for the third research question which aimed at finding if there is a significant difference between the two treatment groups of learners, a significant difference was found. To put it in other words, those who were in the individual feedback group, performed significantly better than those who were in the group feedback group.

One of the reasons why individual feedback group were better than the group feedback, can be because of the social and cultural characteristics of the target culture. In the Iranian context, individual techniques have proved to have more effects than group techniques. Therefore, this can be a contributing factor to why individual feedback was better than group feedback.

Another reason for the results of this research can be due to the fact that when individual feedback is given to learners, they feel that the feedback is exclusive to them and they pay more attention to what the teacher has commented exclusively on their writing assignment. On the other hand, the learners may feed more attention directed towards them when they receive individual feedback than group feedback which is addressed to all students in the class.

Last but not least, some students tend to overlook feedback given to other students and simply move on to the comments the teacher has made about their own writing. This way, confusion can be avoided on the part of the learner. Another factor that needs to be taken into account is that some students may overgeneralize the feedbacks given to their peers and apply them to their writing, where those comments may not be applicable.

The results of this study can have a number of pedagogical implications for foreign language teachers, material developers, EFL learners, and syllabus designers. These pedagogical implications are presented in detail in this section in the following paragraphs.

Teachers can benefit from these findings in several ways. One of the things that can contribute to improvement in teaching quality, is that teachers can take advantage of these results to choose what type of feedback is better to be applied in Iranian learners' writing assignments. Results of this study also provide new insights into teaching pragmatics in EFL contexts. Teaching of speech acts can be a demanding thing and they are very important in improving learners' decision-making when they are supposed to produce language, which is in this case writing. Results of this study also provide new insights into teaching pragmatics in EFL contexts. Teaching of speech acts can be a 
demanding thing and they are very important in improving learners' decision-making when they are supposed to produce language, which is in this case writing. Tests can also focus more on promoting individual feedback among learners and teachers in washback effects.

As for material developers, they can benefit from these findings by designing textbooks, tests and supplemental books that focus more on individual feedback. In fact, different supplemental materials can accompany the textbooks based on the cultural and social features of the target market to make the textbooks more welcomed and effective in these contexts.. Syllabus designers are the other beneficiaries of the results of the present research study. They can design syllabi that emphasize both types of feedback in the classroom. Syllabus designers can incorporate different types of feedback in the syllabus for students with different personalities to take advantage of. It is suggested that group feedback be accompanied with individual feedback for optimal results and benefits.

The findings can also help L2 learners improve their knowledge of pragmatics, especially speech acts, by taking advantage of comments they receive on their produced language. This is important because those learners who receive group feedback, can have a more positive attitude towards it to take the best advantage from it, and those who receive individual feedback, can compare their feedbacks with their partners' and learn more from them.

Despite the interesting findings and implication this study has, some imitations may affect the findings. One is the small sample size in each group (16). A larger sample size in future research can help increase the generalizability of the findings related to this study with respect to the feedback condition effect and speech act in wiritng apology letters. It is suggested that similar studies can be carried out with different dependent variables than this study. The effect of teacher's individual and group feedback can be studied for their effects on writing accuracy, speaking fluency, and the like. Other studies can also be conducted with respect to grouping conditions such as mixed proficiency levels, mixed inter-cultural grouping of students with different cultures of L1 language background. Besides, the potential of online and virtual synchronous and asynchronous platforms besides face-to-face actual classrooms can be investigated to scrutinize how computer mediated instruction can assist speech act learning.

\section{Supplementary information}

Supplementary information accompanies this paper at https://doi.org/10.1186/s40862-020-00088-w.

Additional file 1.

\section{Acknowledgements} not applicable.

Authors' contributions

Zahar Pourmousavi carried out the study, participated in data collection and drafted the manuscript. Zohre Mohamadi Zenouzagh carried out and conceived of the study, participated in its design and coordinated and helped to draft the manuscript and performed the statistical analysis. 
Availability of data and materials

Please contact the authors for data requests.

\section{Competing interests}

The authors declare that they have no competing interests.

Received: 22 January 2020 Accepted: 3 June 2020

Published online: 20 August 2020

\section{References}

Abdi, M. N. (2014). Improving the Writing Ability of the Tenth Grade Students of MA NU TBS Kudus in Academic Year 2013/ 2014 by Chronological 3D Pictures (Doctoral dissertation, Universitas Muria Kudus).

Ahmed, A. H. (2010). Students' problems with cohesion and coherence in EFL essay writing in Egypt: Different perspectives. Literacy Information and Computer Education Journal (LICEJ), 1(4), 211-221.

Ajabshir, Z. F. (2014). The effect of implicit and explicit types of feedback on learners' pragmatic development. Procedia-Social and Behavioral Sciences, 98, 463-471.

Al Masaeed, K., Waugh, L. R., \& Burns, K. E. (2018). The development of interlanguage pragmatics in L2 Arabic: The production of apology strategies. System, 74, 98-108.

Alerwi, A. A., \& Alzahrani, A. (2020). Using sitcoms to improve the Acquisition of Speech Acts by EFL students: Focusing on request, refusal, apology, and compliment response. Journal of Applied Linguistics and Language Research, 7(1), 63-79.

Amini, M., \& Aghvami, S. M. (2009). A concise guide to letter writing. Tehran: Zabankadeh.

Ansarin, A. A., \& Mohamadi, Z. (2013). Language engagement at the level of syntax: Assessing Metatalk and task types in SLA. International Journal of Applied Linguistics and English Literature, 2(4), 142-154.

Ashwell, T. (2000). Patterns of teacher response to student writing in a multiple-draft composition classroom: Is content feedback followed by form feedback the best method? Journal of Second Language Writing, 9(3), 227-257.

Austin, J. L. (1975). How to do things with words (Vol. 88). Oxford: Oxford University Press.

Bly, R. (2011). Webster's New World letter writing handbook. Houghton Mifflin Harcourt.

Bitchener, J., Young, S., \& Cameron, D. (2005). The effect of different types of corrective feedback on ESL student writing. Journal of Second Lanquage Writing, 14(3), 191-205.

Brannon, L., \& Knoblauch, C. H. (1982). On students' rights to their own texts: a model of teacher response. College Composition and Communication, 33(2), 157-166.

Brookhart, S. M. (2017). How to give effective feedback to your students. Alexandria: ASCD.

Canning-Wilson, C., \& Wallace, J. (2000). Practical aspects of using video in the foreign language classroom. The Internet TESL Journal, 6(11), 36-31.

Carbaugh, D. (2013). Cultural communication and intercultural contact. Abingdon: Routledge.

Chandler, J. (2003). The efficacy of various kinds of error feedback for improvement in the accuracy and fluency of L2 student writing. Journal of Second Language Writing, 12(3), 267-296.

Chen, Y. S., \& Liu, J. (2016). Constructing a scale to assess L2 written speech act performance: WDCT and e-mail tasks. Language Assessment Quarterly, 13 (3), 231-250.

Coffin, C., Curry, M. J., Goodman, S., Hewings, A., Lillis, T., \& Swann, J. (2005). Teaching academic writing: A toolkit for higher education. Abingdon: Routledge.

Cohen, A. D. (1987). Student processing of feedback on their compositions. Learner Strategies in Language Learning, 57-69.

Cohen, A. D., \& Sykes, J. M. (2010). Language-learner strategies and their effect on Speech act performance. In Applied Linguistics Forum (Vol. 30, No. 1).

Crandall, E., \& Basturkmen, H. (2004). Evaluating pragmatics-focused materials. ELT Journal, 58(1), 38-49.

DeCapua, A., \& Dunham, J. F. (2007). The pragmatics of advice giving: Cross-cultural perspectives. Intercultural Pragmatics, 4(3), $319-342$.

Delen, B., \& Tavil, Z. M. (2010). Evaluation of four coursebooks in terms of three speech acts: Requests, refusals and complaints. Procedia-Social and Behavioral Sciences, 9, 692-697.

Derakhshan, A., \& Arabmofrad, A. (2018). The impact of instruction on the pragmatic comprehension of speech acts of apology, request, and refusal among Iranian intermediate EFL learners. English Teaching \& Learning, 42(1), 75-94.

Drid, T. (2018). Language as action: Fundamentals of the speech act theory. Praxis International Journal of Social Science and Literature, $1(10), 9$.

Ellis, A. K. (2014). Research on educational innovations. Abingdon: Routledge.

Ellis, R. (2009). Task-based language teaching: sorting out the misunderstandings. International Journal of Applied Linguistics, 19(3), 221-246.

Ellis, R., Basturkmen, H., \& Loewen, S. (2001). Learner uptake in communicative ESL lessons. Language Learning, 51(2), 281 -318.

Ellis, R., Loewen, S., \& Basturkmen, H. (2006). Disentangling focus on form. A response to sheen and O'Neill (2005). Applied Linguistics, 27(1), 135-141.

Evans, N. W., Hartshorn, K. J., McCollum, R. M., \& Wolfersberger, M. (2010). Contextualizing corrective feedback in second language writing pedagogy. Language Teaching Research, 14(4), 445-463.

Fazio, L. L. (2001). The effect of corrections and commentaries on the journal writing accuracy of minority-and majoritylanguage students. Journal of Second Language Writing, 10(4), 235-249.

Ferris, D., \& Roberts, B. (2001). Error feedback in L2 writing classes: How explicit does it need to be? Journal of Second Language Writing, 10(3), 161-184.

Ferris, D. R. (1997). The influence of teacher commentary on student revision. TESOL Quarterly, 31(2), 315-339.

Ferris, D. R. (2004). The "grammar correction" debate in L2 writing: Where are we, and where do we go from here? (and what do we do in the meantime ... ?). Journal of Second Language Writing, 13(1), 49-62.

Ferris, D. R. (2010). Second language writing research and written corrective feedback in SLA: Intersections and practical applications. Studies in Second Language Acquisition, 32(2), 181-201. 
Freedman, S. W. (1985). The acquisition of written language: response and revision. Writing research: multidisciplinary inquiries into the nature of writing series: ERIC.

Gass, S. M., \& Mackey, A. (2007). Input, interaction, and output in second language acquisition. Theories in second language acquisition: An introduction, 175199

Hedgcock, J., \& Lefkowitz, N. (1996). Feedback on feedback: Assessing learner receptivity to teacher response in L2 composing. Journal of Second Language Writing, 3(2), 141-163.

Hinkel, E. (1997). Appropriateness of advice: DCT and multiple choice data 1. Applied Linguistics, 18(1), 1-26.

Hyland, F., \& Hyland, K. (2001). Sugaring the pill: Praise and criticism in written feedback. Journal of Second Language Writing, 10(3), 185-212.

Hyland, K. (2015). Teaching and researching writing. Abingdon: Routledge.

Hyland, K., \& Hyland, F. (2006). Feedback on second language students' writing. Language Teaching, 39(2), 83-101.

Kasper, G. R. K. (2001). Pragmatics in language teaching. Cambridge: Cambridge University Press.

Kissine, M. (2013). From utterances to speech acts. Cambridge University Press.

Krapels, A. R. (1990). An overview of second language writing process research. Second language writing: Research insights for the classroom, 28, 37-56.

Leki, I. (2002). Coaching from the margins: Issues in written response. Second language writing: Research insights for the classroom, 57-68.

Li, S., Taguchi, N., \& Xiao, F. (2019). Variations in Rating Scale Functioning In Assessing Pragmatic Performance in L2 Chinese.

Lockhart, C., \& Ng, P. (1995). Analyzing talk in ESL peer response groups: Stances, functions, and content. Language Learning, 45(4), 605-651.

Long, M. H. (1985). Input and second language acquisition theory. Input in second language acquisition, 377-393.

Maibodi, A. H. (2016). Investigating the Effects of Individual Differences in the Speech Act of Apology in Institutional Discourse Ashraf Haji Maibodi. English Language Teaching, 3(2), 65-88.

Manchón, R. (2011). Learning-to-write and writing-to-learn in an additional language (Vol. 31). Amsterdam: John Benjamins Publishing.

Martínez Flor, A. (2005). A theoretical review of the speech act of suggesting: Towards a taxonomy for its use in FLT. Revista Alicantina de Estudios Ingleses, 18(Nov. 2005), 167-187.

Martínez-Flor, A., \& Usó-Juan, E. (2010). 14. The teaching of speech acts in second and foreign language instructional contexts. Pragmatics Across Languages and Cultures, 7, 423.

Muiis, D. (2004). Doing quantiative research in education with SPSS. London: Sage.

Nation, I. S. (2008). Teaching ESL/EFL reading and writing. Abingon: Routledge.

Petrey, S. (2016). Speech acts and literary theory. Abingon: Routledge.

Pishghadam, R., \& Sharafaddini, M. (2011). Delving into speech act of suggestion: A case of Iranian EFL learners. International Journal of Business and Social Science, 2, 152-160.

Podesta, S., \& Paxton, A. (2003). 201 killer cover letters. McGraw-Hill Companies.

Purver, M., Gregoromichelaki, E., \& Cann, R. (2010). Splitting thel's and crossing theYou's: Context, Speech Acts and Grammar.

Rajabia, S., Azizifara, A., \& Gowhary, H. (2015). The effect of explicit instruction on pragmatic competence development; teaching requests to EFL learners of English. Procedia-Social and Behavioral Sciences, 199(3), 231-239.

Reid, J. (1994). Responding to ESL students' texts: The myths of appropriation. TESOL Quarterly, 28(2), 273-292.

Richards, J. C., \& Schmidt, R. W. (2013). Longman dictionary of language teaching and applied linguistics. Abingdon: Routledge.

Roever, C., Fraser, C., \& Elder, C. (2014). Testing ESL sociopragmatics: development and validation of a web-based test battery. New York: Peter Lang.

Röver, C. (2014). Testing ESL pragmatics: development and validation of a web-based assessment battery. New York: Peter Lang.

Saito, H. (1994). Teachers' practices and students' preferences for feedback on second language writing: A case study of adult ESL learners. TESL Canada Journal, 11(2), 46-70.

Schmidt, R. (1995). Consciousness and foreign language learning: A tutorial on the role of attention and awareness in learning. Attention and Awareness in Foreign Language Learning, 9, 1-63.

Schmidt, R. W. (1990). The role of consciousness in second language learning1. Applied Linguistics, 11(2), 129-158.

Searle, J. R. (1975). A taxonomy of illocutionary acts.

Shafee Nahrkhalaji, S. (2013). The effect of different types of instruction and feedback on the development of pragmatic proficiency: The case of pragmatic markers. Research in English Language Pedagogy, 1(1), 72-83.

Silva, T. (1993). Toward an understanding of the distinct nature of L2 writing: The ESL research and its implications. TESOL Quarterly, 27(4), 657-677.

Slimani, A. (1992). Evaluation of classroom interaction. Evaluating Second Language Education, 197-221.

Straub, R. (2000). The practice of response: strategies for commenting on student writing.

Stubbs, M. (1983). Can I have that in writing, please? Some neglected topics in speech act theory. Journal of Pragmatics, 7(5), 479-494.

Susser, B. (1994). Process approaches in ESL/EFL writing instruction. Journal of Second Language Writing, 3(1), 31-47.

Tatsuki, D. H., \& Houck, N. R. (2010). Pragmatics: teaching speech acts. ERIC.

Taylor, S. (2015). Model business letters, emails and other business documents. UK: Pearson.

Thambirajah, J. I., \& Nordin, N. (2014). Effectiveness of conference feedback on college students' composition in the English as a second language (ESL) context. Research on Humanities and Social Sciences, 4(10), 65-75.

Usó-Juan, E., \& Martínez-Flor, A. (2008). Teaching learners to appropriately mitigate requests. ELT Journal, 62(4), 349-357.

Van Beuningen, C. G., De Jong, N. H., \& Kuiken, F. (2012). Evidence on the effectiveness of comprehensive error correction in second language writing. Language Learning, 62(1), 1-41.

White, L. (1987). Against comprehensible input: The input hypothesis and the development of second-language Competence1. Applied Linguistics, 8(2), 95-110.

White, L. (1989). Universal grammar and second language acquisition (Vol. 1). Amsterdam: John Benjamins Publishing.

Williams, J. (2012). The potential role (s) of writing in second language development. Journal of Second Language Writing, $21(4), 321-331$. 
Wong, J. (2016). A critical look at the description of speech acts. In Interdisciplinary studies in pragmatics, culture and society (pp. 825-855). Berlin: Springer.

Yang, M., Badger, R., \& Yu, Z. (2006). A comparative study of peer and teacher feedback in a Chinese EFL writing class. Journal of Second Language Writing, 15(3), 179-200.

Yule, G. (2016). The study of language. Cambridge: Cambridge University Press.

Zamel, V. (1983). The composing processes of advanced ESL students: Six case studies. TESOL Quarterly, 17(2), 165-188.

Zhang, S. (1995). Reexamining the affective advantage of peer feedback in the ESL writing class. Journal of Second Language Writing, 4, 209-222.

Ziv, N. D. (1984). The effect of teacher comments on the writing of four college freshman. In R. Beach \& L. Bridwell (Eds.), New directions in composition research (pp. 362-380). New York: Guilford Press.

\section{Publisher's Note}

Springer Nature remains neutral with regard to jurisdictional claims in published maps and institutional affiliations.

Submit your manuscript to a SpringerOpen ${ }^{\odot}$ journal and benefit from:

- Convenient online submission

Rigorous peer review

- Open access: articles freely available online

- High visibility within the field

- Retaining the copyright to your article

Submit your next manuscript at $\boldsymbol{\nabla}$ springeropen.com 